\title{
Feasibility of a prototype carbon nanotube enabled stationary digital chest tomosynthesis system for identification of pulmonary nodules by pulmonologists
}

\author{
Allen Cole Burks ${ }^{1} \wedge, J^{2}$ ason Akulian ${ }^{1 \wedge}$, Christina R. MacRosty ${ }^{1 \wedge}$, Sohini Ghosh $^{2}$, Adam Belanger $^{3} \wedge$, \\ Muthu Sakthivel ${ }^{4} \wedge$, Thad S. Benefield ${ }^{4} \wedge$, Christina R. Inscoe ${ }^{5} \wedge$, Otto Zhou ${ }^{5} \wedge$, Jianping Lu ${ }^{5}$, \\ Yueh Z. Lee ${ }^{4} \wedge$ \\ ${ }^{1}$ Division of Pulmonary and Critical Care Medicine, University of North Carolina at Chapel Hill, NC, USA; ${ }^{2}$ Division of Pulmonary and Critical Care, \\ Allegheny Health Network, Pittsburgh, PA, USA; ${ }^{3}$ FirstHealth, Pinehurst Medical Clinic, Pinehurst, NC, USA; ${ }^{4}$ Department of Radiology, University \\ of North Carolina at Chapel Hill, NC, USA; ${ }^{5}$ Department of Physics and Astronomy, University of North Carolina at Chapel Hill, NC, USA \\ Contributions: (I) Conception and design: AC Burks, YZ Lee; (II) Administrative support: YZ Lee; (III) Provision of study materials or patients: YZ \\ Lee, CR Inscoe, O Zhou, J Lu; (IV) Collection and assembly of data: AC Burks, J Akulian, CR Macrosty, S Ghosh, A Belanger, M Sakthivel; (V) Data \\ analysis and interpretation: AC Burks, YZ Lee, TS Benefield; (VI) Manuscript writing: All authors; (VII) Final approval of manuscript: All authors. \\ Correspondence to: Allen Cole Burks, MD. Campus Box 7219, 160 Dental Circle, Chapel Hill, NC 27559, USA. Email: acole_burks@med.unc.edu.
}

Background: Screen detected and incidental pulmonary nodules are increasingly common. Current guidelines recommend tissue sampling of solid nodules $>8 \mathrm{~mm}$. Bronchoscopic biopsy poses the lowest risk but is paired with the lowest diagnostic yield when compared to CT-guided biopsy or surgery. A need exists for a safe, mobile, low radiation dose, intra-procedural method to localize biopsy instruments within target nodules. This retrospective cross sectional reader feasibility study evaluates the ability of clinicians to identify pulmonary nodules using a prototype carbon nanotube radiation enabled stationary digital chest tomosynthesis system.

Methods: Patients with pulmonary nodules on prior CT imaging were recruited and consented for imaging with stationary digital chest tomosynthesis. Five pulmonologists of varying training levels participated as readers. Following review of patient CT and a thoracic radiologist's interpretation of nodule size and location the readers were tasked with interpreting the corresponding tomosynthesis scan to identify the same nodule found on CT.

Results: Fifty-five patients were scanned with stationary digital chest tomosynthesis. The median nodule size was $6 \mathrm{~mm}(\mathrm{IQR}=4-13 \mathrm{~mm})$. Twenty nodules $(37 \%)$ were greater than $8 \mathrm{~mm}$. The radiation entrance dose for s-DCT was $0.6 \mathrm{mGy}$. A significant difference in identification of nodules using s-DCT was seen for nodules $<8$ vs. $\geq 8 \mathrm{~mm}$ in size $(57.7 \%$ vs. $90.9 \%$, CI: $-0.375,-0.024 ; \mathrm{P}<0.001)$. Inter-reader agreement was fair, and better for nodules $\geq 8 \mathrm{~mm}[0.278$ (SE =0.043)].

Conclusions: With system and carbon nanotube array optimization, we hypothesize the detection rate for nodules will improve. Additional study is needed to evaluate its use in target and tool co-localization and target biopsy.

Keywords: Tomosynthesis; pulmonary nodules; lung cancer; chest imaging; bronchoscopy

\footnotetext{
^ ORCID: Allen Cole Burks, 0000-0002-0208-3335; Jason Akulian, 0000-0002-4528-8496; Christina R. MacRosty, 0000-0001-6344-4408; Adam Belanger, 0000-0002-9149-9147; Muthu Sakthivel, 0000-0002-6257-884X; Thad S. Benefield, 0000-0002-4218-3330; Christina R. Inscoe, 0000-0001-8681-9030; Otto Zhou, 0000-0003-1476-5517; Jianping Lu, 0000-0001-9963-9741; Yueh Lee, 0000-0003-1846-7680.
} 
Submitted Aug 22, 2021. Accepted for publication Dec 30, 2021.

doi: $10.21037 /$ jtd-21-1381

View this article at: https://dx.doi.org/10.21037/jtd-21-1381

\section{Introduction}

Lung cancer screening is associated with a $20 \%$ decreased risk of lung cancer mortality by shifting toward earlier stages at diagnosis $(1,2)$. Lung cancer screening and increasing use of chest computed tomography (CT) continues to result in increasing detection of peripheral lung nodules (PLN) (3). Current guidelines recommend tissue sampling of solid nodules $>8 \mathrm{~mm}$ based on an increase in risk from $0.5-2 \%$ for nodules $<8 \mathrm{~mm}$ to $>3 \%$ for those $>8 \mathrm{~mm}(4,5)$. Surgical resection (SR) remains the gold standard for definitive diagnosis and cure for nodules $8 \mathrm{~mm}$ to $7 \mathrm{~cm}$, however is associated with postoperative complication rates of $14.9-29.1 \%$ for video assisted thoracoscopic surgery $v$. $25.1-47.8 \%$ for open thoracotomy (6). Given that $>90 \%$ of CT detected nodules are benign, recommendations state that intermediate risk patients and poor surgical candidates should undergo minimally invasive sampling prior to definitive management (7). Bronchoscopic biopsy of PLN has an acceptably low procedural risk, but remains plagued by low diagnostic yields (8-11). The gap between lesion localization and diagnosis is increasingly recognized as related to a lack of real time confirmation of tool to nodule co-localization $(12,13)$. A need exists for a safe, mobile, low radiation dose intra-procedural method to co-localize biopsy instruments to target nodules.

Single projection radiographs and single or bi-plane fluoroscopy have offered little utility in defining the 3-D co-localization of biopsy tool to nodules (14-16). While CT offers multiplanar 3-D information, its size, radiation dose $(\sim 1.5 \mathrm{mSv}$ for an average sized patient in a low-dose chest CT protocol), and cost significantly limits its utility (17). Cone-beam CT (CBCT) has been investigated for intraoperative imaging and employs a large area detector that results in a lower radiation dose compared to fan-beam helical scanners but suffers from lower image quality and artifacts near the field of view edge (18-22). Current CBCT systems lack respiratory gating capabilities, require $\sim 180^{\circ}$ mechanical X-ray source and detector rotation around the patient with typical scan times of $\sim 30 \mathrm{~s}$, and require the procedure room to be vacated during scanning times (19). Reported mean radiation doses for augmented fluoroscopyCBCT procedures for PLN bronchoscopy are $~ 3-3.7 \mathrm{mSv}$
(2 mSv per CBCT scan) $(23,24)$. The physical footprint, cost, and radiation exposure related to CBCT may be prohibitive in many bronchoscopy practices.

Tomosynthesis is a 3 -dimensional imaging technique providing reconstruction planes from a limited-angle series of projection images (Figure 1) $(25,26)$. Previous studies of tomosynthesis have demonstrated its ability to deliver fast, low dose, and high-quality images (25,27-30). The technique provides excellent landmark localization with high spatial orientation of lesion and adjacent vital structures. Commercially available conventional Digital Chest Tomosynthesis (c-DCT) systems collect X-ray projection images by mechanically moving a single $\mathrm{X}$-ray source to different viewing angles. A typical DCT scan uses $\sim 60$ projections over $30^{\circ}$ in 10 seconds (31-33). The projections are digitally reconstructed into image "slices" with high in-plane resolution, and significantly lower radiation dose compared to $\mathrm{CT}$.

Conventional DCT has been investigated for intraoperative imaging $(34,35)$. Prior studies have reported that c-DCT provides near-real-time images of surgical and peripheral lung targets and related structures at an effective radiation dose of $0.13 \mathrm{mSv}$, an order of magnitude less than typical diagnostic CT (1-4 mSv) (35-37). Use of c-DCT can result in an effective dose reduction of $2 \mathrm{mSv}$ per procedure (0.7 mSv with c-DCT vs. $2.7 \mathrm{mSv}$ with CT) (38). These studies utilized a single $\mathrm{X}$-ray source on a moving gantry, resulting in scan times $\sim 10 \mathrm{sec}$. Similar to CBCT, c-DCT has been difficult to incorporate as a procedural imaging platform as the cost and size can limit device access for bronchoscopists.

We present here a reader feasibility study of retrospectively reviewed images created by a novel, prototype carbon nanotube (CNT) X-ray source enabled stationary digital chest tomosynthesis system (s-DCT). The system was previously shown to have an entrance dose of $0.6 \mathrm{mGy}$; comparable to standard chest X-ray systems ( 0.31 to $0.88 \mathrm{mGy}$ ) and c-DCT systems ( 0.31 to $1.27 \mathrm{mGy})$ $(28,39,40)$. We hypothesize that pulmonology clinicians can identify CT detected nodules using the prototype s-DCT system with high confidence and inter reader agreement. The system has the following technical features: (I) stationary X-ray source and detector, (II) low radiation 

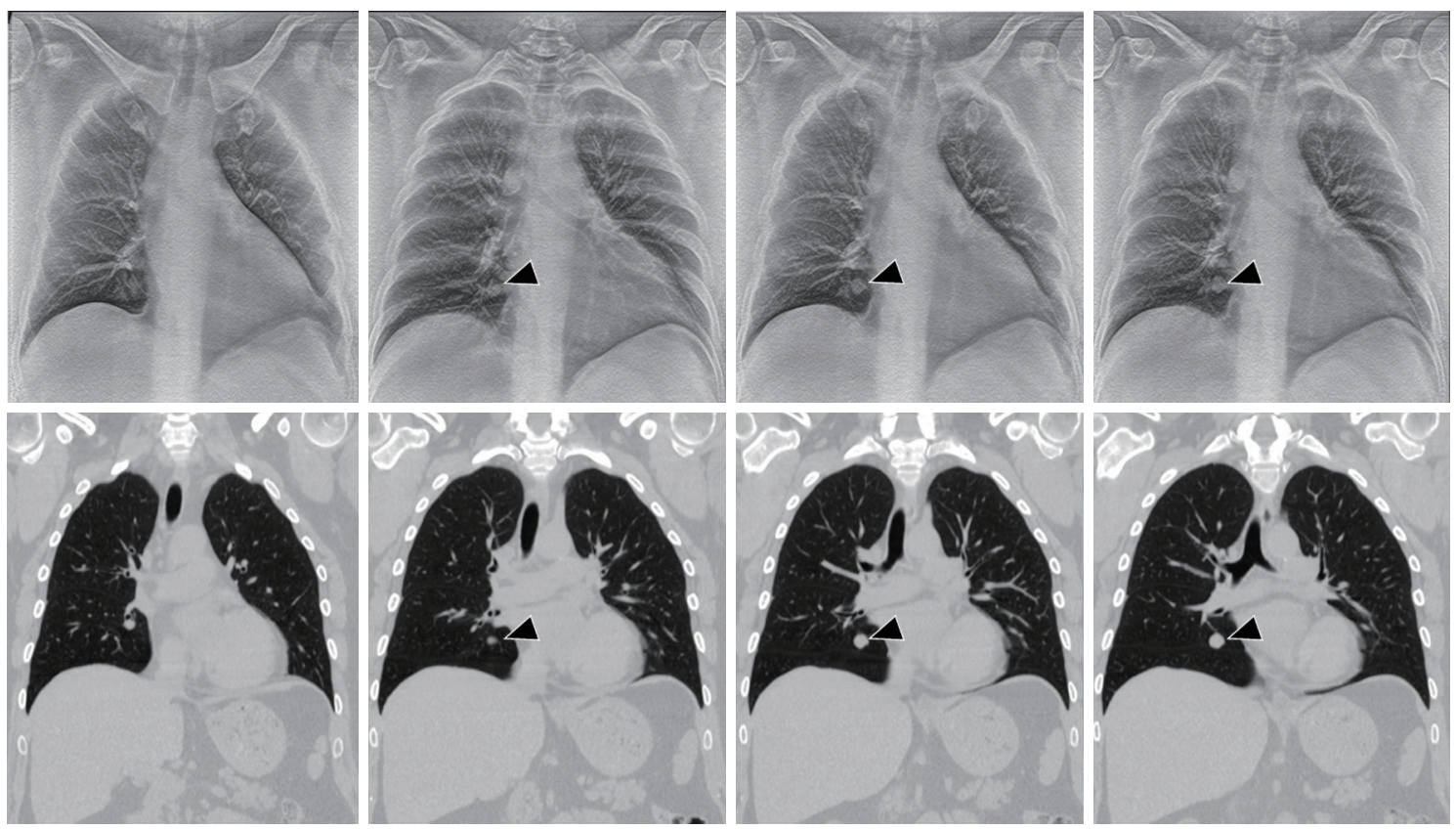

Figure 1 Top panel: series of Tomosynthesis images obtained with the novel stationary digital chest tomosynthesis system. Bottom panel: series of coronal slices from a CT of the same patient. Arrow heads = solid pulmonary nodule.

dose, (III) rapid scan times of $\leq 2 \mathrm{~s}$; (IV) high in-plane $(<1 \mathrm{~mm})$ resolution; (V) the ability to operate in biplane mode of localization; and (VI) compact, portable design $(41,42)$. The current study serves as a feasibility assessment for pre-procedural nodule detection by proceduralists as clinical background data for ongoing preclinical optimization and development of an s-DCT based real time transbronchial biopsy guidance system. We present the following article in accordance with the STROBE reporting checklist (available at https://jtd.amegroups.com/article/ view/10.21037/jtd-21-1381/rc).

\section{Methods}

The study was conducted in accordance with the Declaration of Helsinki (as revised in 2013). The study is compliant with the Health Insurance Portability and Accountability Act, approved by the University of North Carolina at Chapel Hill (UNC) Institutional Review Board (No. UNC IRB 13-3345), and the data was obtained as part of a registered Clinical Trial at ClinicalTrials.gov (NCT02075320). Written and oral informed consent was obtained from each subject.

\section{Patient population, inclusion and exclusion criteria}

Patients with PLN identified on CT undergoing followup imaging were recruited through collaboration with the UNC Multidisciplinary Thoracic Oncology Program for involvement in a clinical trial to assess the sensitivity of s-DCT detection of lung nodules for lung cancer screening follow up. Inclusion criteria included a CT scan within a 4-week period of enrollment, age $\geq 18$ years of age, and no interval thoracic procedures. Exclusion criteria included pregnancy, prior thoracic surgery, and body mass index (BMI) greater than 33. The CT scans were obtained per routine clinical care at UNC Hospital, and the s-DCT images were obtained at the UNC-CH Biomedical Research Imaging Center on a volunteer basis after informed consent within 4 weeks of the clinical CT scan. The images were obtained from February 2014 to August 2016 and the current reader study data was gathered from July 2018 to June 2019 as a post-hoc analysis of the clinical trial.

\section{s-DCT reader study}

Three board-certified interventional pulmonologists, 
Stationary Chest Tomosynthesis Nodule Localization Reader Study

Study CS-01

Reader \#

Date

Radiologist Nodule Report: 12.6 mm RML pure solid, round nodule. Slice 3IMA43

Reader views the CT (circle the number that most closely matches your evaluation)

1. Confidence in identification of reported lesion on CT scan:

\begin{tabular}{|c|c|c|c|c|}
\hline 1 & 2 & 3 & 4 & 5 \\
\hline $\begin{array}{c}\text { Definitely no } \\
\text { lesion }\end{array}$ & $\begin{array}{c}\text { Probably no } \\
\text { lesion }\end{array}$ & Equivocal & Probably lesion & Definitely lesion \\
\hline
\end{tabular}

Reader views the Tomosynthesis (circle the number that most closely matches your evaluation)

2. Confidence in the presence of a lesion on Tomosynthesis:

\begin{tabular}{|c|c|c|c|c|}
\hline 1 & 2 & 3 & 4 & 5 \\
\hline $\begin{array}{c}\text { Definitely no } \\
\text { lesion }\end{array}$ & $\begin{array}{c}\text { Probably no } \\
\text { lesion }\end{array}$ & Equivocal & $\begin{array}{c}\text { Probably } \\
\text { pulmonary } \\
\text { lesion }\end{array}$ & $\begin{array}{c}\text { Definitely } \\
\text { pulmonary } \\
\text { lesion }\end{array}$ \\
\hline
\end{tabular}

If the confidence rating is 3 or greater $(3,4$ or 5$)$ :

3. Confidence that the lesion on Tomosynthesis represents the same lesion seen on CT scan: (circle the number that most closely matches your evaluation)

\begin{tabular}{|c|c|c|c|c|}
\hline 1 & 2 & 3 & 4 & 5 \\
\hline $\begin{array}{c}\text { Definitely not } \\
\text { same lesion }\end{array}$ & $\begin{array}{c}\text { Probably not } \\
\text { same lesion }\end{array}$ & Equivocal & $\begin{array}{c}\text { Probably same } \\
\text { lesion }\end{array}$ & $\begin{array}{c}\text { Definitely same } \\
\text { lesion }\end{array}$ \\
\hline
\end{tabular}

Figure 2 Example of reader score sheet with radiologist nodule report.

one interventional pulmonology fellow, and one general pulmonology fellow performed the retrospective crosssectional reader studies. This was the first experience with DCT for each reader and they were blinded to all clinical data. In order to avoid inter-reader nodule selection bias, an independent board-certified thoracic radiologist reviewed and provided a standardized read of each CT scan, including nodule size, location and CT slice number, characteristics, and presence of emphysema. The readers were instructed to identify only the nodule noted on the radiologist's interpretation in order to reduce variability of nodules identified as multiple cases had multiple nodules. Images were reviewed on an offline workstation with medicalgrade 3-megapixel picture archiving and communication system (PACS) monitors. Readers reviewed the s-DCT images and their corresponding CT scans in the axial and coronal planes. Standard image software evaluation tools (magnification, window/leveling) were available.
The readers evaluated each CT scan and report (Figure 2), then recorded their ability to recognize the radiologist reported nodule on CT scan. Following this, the readers attempted to identify the same nodule on the s-DCT image stack. The readers were permitted to compare both modalities as many times as necessary to adequately answer the question. The reader's ability to identify a nodule on s-DCT was self-reported on a Likert scale of 1 (poor) to 5 (high). The reader's confidence that the nodule identified on s-DCT was the same as that identified by the radiologist on CT scan was reported on a similar scale of 1 to 5 .

\section{s-DCT and CT imaging systems}

CT studies were performed on conventional 64 slice clinical CT systems, and presented for review in $3 \mathrm{~mm}$ coronal slices when available. Otherwise, axial $5 \mathrm{~mm}$ slices were presented for review. 

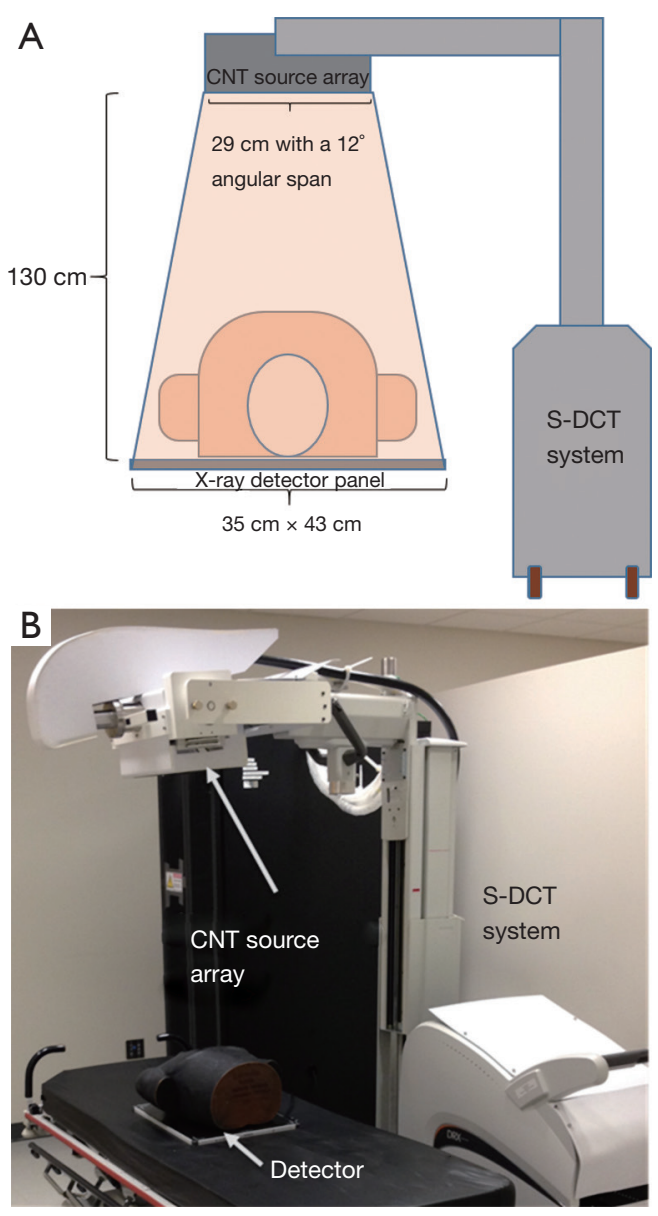

Figure 3 Prototype s-DCT system used in this study. (A) Diagram of the s-DCT system. (B) Photo of the s-DCT system. s-DCT, stationary digital chest tomosynthesis; CNT, carbon nano tube.

The s-DCT system is based on a linear CNT X-ray source array, combined with a commercially available highspeed digital X-ray detector. The imaging system consists of a CNT X-ray source array with a linear cathode pixel array, which consists of 75 available $\mathrm{X}$-ray sources across $29 \mathrm{~cm}$, of which 29 sources were utilized for the study. The tube's high voltage acceleration limit was $80 \mathrm{kVp}$. The anode consists of a tungsten target with an exit window with $2.5 \mathrm{~mm}$ of aluminum filtration. The imaging setup uses a source to detector distance of $130 \mathrm{~cm}$ to achieve a 12-degree angular coverage (Figure 3).

The measured focal spot size was $2.5 \mathrm{~mm}$ by $0.5 \mathrm{~mm}$ $(27,28)$. The flat panel silicon detector measures $35 \mathrm{~cm}$ by $43 \mathrm{~cm}$ with a $139 \mathrm{~mm}$ pixel size and acquisition rate of $10 \mathrm{fps}$. The system resolution was 1.7 cycles/mm in scan direction and 3.4 cycles $/ \mathrm{mm}$ in the perpendicular direction. The entrance radiation dose for adult patients is $0.6 \mathrm{mGy}$ (43).

\section{s-DCT image reconstruction}

The acquired projection data was reconstructed using Adapted Fan-beam Volume Reconstruction with custom code written in Matlab (Mathworks, Inc., Natick, MA, USA). The method is optimized for the linear source array and transforms the $3 \mathrm{D}$ cone-beam reconstruction into a series of 2D fan-beam volume reconstructions with DCT slice thickness of $3 \mathrm{~mm}$ in the coronal direction (43).

\section{Statistical analysis}

Statistical analysis was performed using SAS Version 9.4 (Cary, NC, USA) software. As a retrospective cross sectional feasibility reader study, a power analysis was not created given the lack of a comparator arm. A mixed effects logistic regression model was used to correlate results within readers as a G-side random effect and correlated within the same nodules as an R-sided compound symmetric random effect. For the multivariate analysis, the $90^{\text {th }}$ percentile, median, and $10^{\text {th }}$ percentile size were used to predict probability of nodule identification. Fleiss' kappa statistic was used to assess reader agreement for all nodule sizes, nodules $<8 \mathrm{~mm}$, nodules $\geq 8 \mathrm{~mm}$, according to training level, and according to number of tomosynthesis images analyzed. The bootstrapping method was used to derive standard errors for the kappas to conduct statistical tests of equality.

\section{Results}

Fifty-five patient CT scans and accompanying s-DCT scans were utilized in this study. The mean and median nodule size was 9.5 and $6 \mathrm{~mm}$ (IQR $25-75=4-13 \mathrm{~mm}$; SD $= \pm 8.43 \mathrm{~mm}$ ), respectively. The $90^{\text {th }}$ percentile of size was $19 \mathrm{~mm}$ and the $10^{\text {th }}$ percentile was $3 \mathrm{~mm}$ (Table 1 ). Twenty (37\%) nodules were greater than $8 \mathrm{~mm}$ in size. Twenty-nine $(52.7 \%)$ nodules were located in the upper lobes. Regarding nodule characteristics: 45 were pure solid (81.8\%), 5 were pure ground glass opacities (GGO) (9\%), 2 were mixed solid-GGO (3.6\%), and 3 were cavitary (5.5\%). Emphysema was present in 27 (49.1\%) scans (Table 2).

\section{Factors of nodule identification}

The unadjusted probability for identification on s-DCT was $68.4 \%$. For nodules $\geq 8 \mathrm{~mm}$, the unadjusted probability 
Table 1 Mean Nodule Sizes including percentiles and interquartile range

\begin{tabular}{lc}
\hline Nodule size & $\mathrm{mm}(\mathrm{SD})$ \\
\hline Mean & $9.50(1.07-17.93)$ \\
IQR & 2 \\
Minimum & 4.00 \\
25th quartile & 6.00 \\
Median & 13.35 \\
75th quartile & 43.10 \\
Maximum & 9.35 \\
IQ range & \\
Percentile & 3.00 \\
10th percentile & 6.00 \\
Median & 18.94 \\
90th percentile & \\
\hline
\end{tabular}

IQR, interquartile range; SD, standard deviation

for identification was $85.7 \%$ compared to $57.7 \%$ for those $<8 \mathrm{~mm}$ in size. When adjusted for location, pure solid, mixed GGO, pure GGO, and nodule appearance, the probability for identification of nodules $\geq 8 \mathrm{~mm}$ was $90.9 \%$ compared to $56.7 \%$ for $<8 \mathrm{~mm}$ (CI: -0.375 , -0.024; $\mathrm{P}<0.001)$. In multi-variate analysis, predictors of identification included increasing nodule size and if the nodule was pure solid. The predicted probability for identification of nodules in the $90^{\text {th }}$ percentile $(19 \mathrm{~mm})$, median $/ 50^{\text {th }}$ percentile $(6 \mathrm{~mm})$, and $10^{\text {th }}$ percentile $(3 \mathrm{~mm})$ of was $94.4 \%, 63.1 \%$, and $50.7 \%$ respectively $(\mathrm{P}=0.0021)$. Pure solid nodules had an odds ratio for identification of 7.93 (95\% CI: 2.31, 27.28), compared to mixed GGO and pure GGO with odds ratio of 0.063 (95\% CI: 0.006, 0.638) and 0.104 (95\% CI: $0.020,0.553)$ respectively.

There was no significant difference in identification based on laterality, or lobar distribution; regardless of nodule size $\geq 8 \mathrm{~mm}(\mathrm{P}=0.60)$. Central $v$ s. peripheral location did not affect identification for either $\geq 8 \mathrm{~mm}(\mathrm{P}=0.84)$ or $<8 \mathrm{~mm}(\mathrm{P}=0.56)$. Similarly, the presence of emphysema on the CT scan did not affect nodule identification (Table 3).

\section{Reader agreement comparison}

Inter-reader agreement was fair for confidence to identify nodules on s-DCT ("identification") with a Fleiss's kappa
Table 2 Distribution of computed tomography scan nodule characteristics

\begin{tabular}{|c|c|}
\hline Scan/nodule characteristic $(\mathrm{N}=55)$ & $\mathrm{N}(\%)$ \\
\hline \multicolumn{2}{|l|}{ Parenchyma } \\
\hline Emphysema & $27(49.1)$ \\
\hline No Emphysema & $28(50.9)$ \\
\hline \multicolumn{2}{|l|}{ Size } \\
\hline$\geq 8 \mathrm{~mm}$ & $20(37.0)$ \\
\hline$<8 \mathrm{~mm}$ & $34(63.0)$ \\
\hline \multicolumn{2}{|l|}{ Location } \\
\hline RUL & $15(27.3)$ \\
\hline RML & $7(12.7)$ \\
\hline RLL & $8(14.6)$ \\
\hline LUL & $14(25.5)$ \\
\hline LLL & $10(18.2)$ \\
\hline Lingula & $1(1.8)$ \\
\hline Central & $23(41.8)$ \\
\hline Peripheral & $32(58.2)$ \\
\hline \multicolumn{2}{|l|}{ Characteristic } \\
\hline Pure Solid & $45(81.8)$ \\
\hline Pure GGO & $5(9.1)$ \\
\hline Mixed & $2(3.6)$ \\
\hline Cavitary & $3(5.5)$ \\
\hline Spiculated & $12(21.8)$ \\
\hline Round & $34(61.8)$ \\
\hline Lobulated & $6(10.9)$ \\
\hline
\end{tabular}

RUL, right upper lobe; RML, right middle lobe; RLL, right lower lobe; LUL, left upper lobe; LLL, left lower lobe; GGO, ground glass opacity.

value of 0.197 ( $\mathrm{SE}=0.022$ ) and confidence in the nodule identified on s-DCT being the same as that described on CT scan ("same") was marginally poorer, with a Fleiss' kappa value of 0.137 ( $\mathrm{SE}=0.025)$. Inter-reader agreement for "identification" improved but remained fair for nodules $\geq 8 \mathrm{~mm}$ with kappa values of $0.278(\mathrm{SE}=0.043)$. The kappa was also improved for "same" in nodules $\geq 8 \mathrm{~mm}$ at 0.182 ( $\mathrm{SE}=0.046$ ). Agreement was poor for nodules $<8 \mathrm{~mm}$ with kappa values of $0.071(\mathrm{SE}=0.030)$ and $0.052(\mathrm{SE}=0.035)$ for "identification" and "same", respectively (Table 4). 
Table 3 Probability of Identification by univariate and multivariate analysis

\begin{tabular}{|c|c|c|c|}
\hline Variable & Adjusted probability of Identification (\%) & $95 \% \mathrm{Cl}$ & $P$ value \\
\hline \multicolumn{4}{|l|}{ Univariate analysis } \\
\hline \multicolumn{4}{|l|}{ Size } \\
\hline$\geq 8 \mathrm{~mm}$ & 90 & & \\
\hline$<8 \mathrm{~mm}$ & 56.7 & & $<0.001$ \\
\hline \multicolumn{4}{|l|}{ Location } \\
\hline RUL & 68.7 & {$[46.5-84.8]$} & \\
\hline RML & 81 & {$[52.6-94.2]$} & \\
\hline RLL & 80.7 & {$[54.1-93.7]$} & \\
\hline LUL & 57.7 & {$[35.6-77.1]$} & \\
\hline \multicolumn{4}{|l|}{$<8 \mathrm{~mm}$} \\
\hline \multicolumn{4}{|l|}{$\geq 8 \mathrm{~mm}$} \\
\hline Peripheral & 86.1 & {$[50.3-81.9]$} & \\
\hline \multicolumn{4}{|l|}{$<8 \mathrm{~mm}$} \\
\hline \multicolumn{4}{|l|}{$\geq 8 \mathrm{~mm}$} \\
\hline \multicolumn{4}{|l|}{ Emphysema present? } \\
\hline Yes & 72.9 & {$[54.8-85.7]$} & \\
\hline No & 65.6 & {$[46.9-80.5]$} & \\
\hline Radiographic consistency & Odds ratio & & \\
\hline Solid & 7.93 & [2.31-27.28] & 0.001 \\
\hline Mixed solid/GGO & 0.063 & {$[0.006-0.0638]$} & \\
\hline Pure GGO & 0.104 & {$[0.020-0.533]$} & \\
\hline
\end{tabular}

RUL, right upper lobe; RML, right middle lobe; RLL, right lower lobe; LUL, left upper lobe; LLL, left lower lobe; GGO, ground glass opacity; $\mathrm{Cl}$, confidence interval.

\section{Discussion}

Bronchoscopic approaches to biopsy of peripheral and small nodules $(<2 \mathrm{~cm})$ are associated with low diagnostic yields and poor negative likelihood ratios despite reports of high rates of nodule localization with radial ultrasound (44-46). Such a discrepancy during guided bronchoscopy may be due to CT-to-body divergence/registration error, a deficiency in currently available biopsy tools, and/or lack of real time confirmation of intraprocedural tool location. We have developed a novel carbon-nanotube s-DCT system that can create images on par with c-DCT systems in terms of radiation dose, scan times, and image quality without 
Table 4 Inter reader agreement with Fleiss's kappa value and standard error in parenthesis

\begin{tabular}{lccccc}
\hline Variable & \multicolumn{2}{c}{ Identified? } & \multicolumn{2}{c}{ Same? } \\
\hline Size & Kappa (SE) & \%Agree (\%1-off) & & Kappa (SE) & \%Agree (\%1-off) \\
\hline All & $0.197(0.022)$ & $10.9(29.1)$ & & $0.137(0.025)$ & $1.8(3.6)$ \\
$<8 \mathrm{~mm}$ & $0.071(0.03)$ & $0(11.7)$ & & $0.052(0.035)$ & $2.9(5.9)$ \\
$\geq 8 \mathrm{~mm}$ & $0.278(0.043)$ & $28.6(57.1)$ & & $0.182(0.046)$ & $0(0)$ \\
\hline
\end{tabular}

SE, standard error.

the need for a moving gantry. We hypothesize that this technology can be used for real time bronchoscopic lung nodule biopsy guidance and tool localization. Potential advantages to using an s-DCT image based navigation and real time confirmation system are: (I) a decrease in radiation dose without sacrificing image quality, (II) decrease in scan time, and thus procedural times, (III) no need to clear the procedural room at the time of scanning, and (IV) smaller physical footprint, decreasing procedural suite crowding.

First, we seek to show the feasibility for the system to identify the nodules for procedural guidance. In our study, we attempted to recreate a clinical scenario similar to what a proceduralist would encounter when evaluating a patient for potential biopsy of a PLN: starting with identification of a CT detected nodule in a patient assumed to be at high risk for lung cancer (for the purposes of this study), then evaluating the s-DCT images in an effort to identify the PLN seen on CT, with the hypothesis that the s-DCT images would be adequate for a proceduralist to identify, at a high rate, nodules that would be potential targets for biopsy. In our model, we found that the rate of identification of clinically significant nodules (defined by Fleischner society guidelines as $\geq 8 \mathrm{~mm}$ in intermediate-high risk patients) was significantly higher than those $<8 \mathrm{~mm}$ (>90\% vs. 57\%) (5). When evaluating the effect of nodule radiographic consistency (solid vs. mixed-solid/GGO) on reader s-DCT identification, pure solid nodules were nearly 8 times more likely to be identified. These data suggests that the novel s-DCT system represents a feasible modality for the peri-operative identification of nodules. The cutoff point of $8 \mathrm{~mm}$ was used in the analysis due to society guidelines for consideration of biopsy $>8 \mathrm{~mm}$ and the increased risk of cancer at that inflection point (4). In clinical practice, PLN $<8 \mathrm{~mm}$ are rarely targets of biopsy, except in very high lung cancer risk patients, or evaluation for metastasis. Nodules $<8 \mathrm{~mm}$ made a majority of our data set, owing to the original purpose of evaluating s-DCT as an alternative to CT scan for lung nodule detection. The preponderance of smaller nodules helped to eliminate scan selection bias giving a more accurate rate of detection across nodules sizes. However, the same preponderance of small nodules may have contributed to the overall poor interreader agreement. The rate of detection and inter-reader agreement on s-DCT may be higher when the median nodule size is $>8 \mathrm{~mm}$, as is encountered in clinical practice when targeting PLN for biopsy. A prospective study utilizing the same prototype system is underway to evaluate the identification nodules that are clinically targetable for biopsy.

The inter-reader agreement was better for identification of the nodule on CT scan than on s-DCT, which was expected, given familiarity with interpreting $\mathrm{CT}$ as opposed to s-DCT images. Nodule size appeared to be a major driver of inter-reader agreement as nodules $\geq 8 \mathrm{~mm}$ were agreed upon with a higher frequency than those $<8 \mathrm{~mm}$. For confidence in detecting the same nodule on s-DCT as on CT scan, inter-reader agreement was poor, indicating that the readers' confidence in what they were observing compared to the CT scan was not uniform. This may be explained by a combination of a prototype s-DCT system not optimized for thoracic imaging, and a lack of familiarity with the imaging modality. An adequate training data set for interpreting lung s-DCT images has not been developed, nor has a learning curve been established. These would be a topic of further research.

One limitation of our study is the prototypical nature of the s-DCT system used and the specific carbonnanotube $\mathrm{X}$-ray tube that has not been optimized for the spatial distinction of specific focal areas of interest. For example, at the time of the study, the tube was limited to $80 \mathrm{kVp}$, whereas conventional $\mathrm{X}$-ray based chest imaging is performed at $120 \mathrm{kVp}$. However, this is not a fundamental limitation of the CNT technology, and higher energy $\mathrm{X}$-ray tubes are now available and are being studied by 
our group in a large animal study as previously mentioned (47). This may explain the poor performance of the system in identifying sub-solid lesions (Table 3). Additionally, as a feasibility study for target nodule identification, this study does not address intra-procedural changes that may affect ongoing nodule discrimination from procedurally induced artifacts such as localized bleeding, atelectasis, mucous plugging, however it is encouraging that the vast majority of clinically actionable nodules were identifiable with an acceptable inter-reader agreement. Plus, the quality and clarity of the s-DCT images were not assessed or compared between readers. This is a point of potential future study as the s-DCT system is further optimized and approaches clinical trials. An increase in angular span from the $12^{\circ}$ to a more standard $30-60^{\circ}$ angular span would be expected to result in both improved depth of resolution and spatial differentiation, thereby improving the ability to resolve lesions from background lung parenchyma and potential procedure induced artifacts (26). Our data is consistent with a previous study of traditional c-DCT systems with higher angular spans $\left(\geq 20^{\circ}\right)$ that achieved detection rates of $90 \%$ for nodules $>10 \mathrm{~mm}, 71 \%$ for nodules $5-10 \mathrm{~mm}$, and $53 \%$ for nodules $3-5 \mathrm{~mm}$ (nodules ranging from 3.5 to $25.5 \mathrm{~mm}$ and a mean of $7.3 \mathrm{~mm}$ ) (48); suggesting that an s-DCT system with a greater angular span could further improve intra-procedural detection of clinically actionable lung nodules. A fully clinically adapted system would be comparable to CBCT and commercially available c-DCT systems that utilize $120 \mathrm{kVp}$, and would be paired with a computerized navigational system relying solely on the s-DCT images, replacing additional planning CT scans, potentially further limiting overall radiation doses. Ongoing preclinical animal studies using an optimized $45^{\circ}$ angular span X-ray source using $120 \mathrm{kVp}$ seeks to develop a same day, intraprocedural bronchoscopic lung nodule biopsy guidance system that does not require clearing of the procedure room for scanning, creates images for navigation planning at the time of the procedure, and allows for realtime tomosynthesis guidance of biopsy tool location.

Further limiting the real word generalizability of the current study is the exclusion of patients with BMI $>33$. This criteria was due to the decreased $\mathrm{X}$-ray penetration and image degradation in obese patients at lower $\mathrm{X}$-ray energies, such as the $80 \mathrm{kVp}$ used by current prototype tube (49).

This study suggests that s-DCT may represent a feasible modality to identify nodules being considered for biopsy. Further study is required with an optimized s-DCT system to determine the feasibility in obese patients and for intraprocedural tool to lesion co-localization and improved lesion discrimination from background lung parenchyma and procedure related artifacts.

\section{Acknowledgments}

We appreciate the technical assistance of Allison Hartman. Funding: The work was supported by the University of North Carolina - Chapel Hill, University Cancer Research Fund of the Lineberger Comprehensive Clinical Cancer Center (No. LCC1337). Some of the equipment utilized in this study was on loan from Carestream Health (Rochester, NY, USA).

\section{Footnote}

Reporting Checklist: The authors have completed the STROBE reporting checklist. Available at https://jtd. amegroups.com/article/view/10.21037/jtd-21-1381/rc

Data Sharing Statement: Available at https://jtd.amegroups. com/article/view/10.21037/jtd-21-1381/dss

Peer Review File: Available at https://jtd.amegroups.com/ article/view/10.21037/jtd-21-1381/prf

Conflicts of Interest: All authors have completed the ICMJE uniform disclosure form (available at https://jtd. amegroups.com/article/view/10.21037/jtd-21-1381/coif) and report that the current study was partially funded by the institutional University Cancer Research Fund via a Lineberger Comprehensive Clinical Cancer Center award. CI reports that she is co-inventor of the tomosynthesis system and received royalties from UNC for the intellectual property (IP). OZ, JL, CI and YL are co-inventors of the stationary chest tomosynthesis imaging system evaluated in this study. OZ and JL are co-owners of Xintek, Inc., the company to which the technology has been licensed. OZ and JL report that they are shareholders and consultants for the company that the IP is licensed to. YL reports that he is co-inventor of the system, but does not receive financial or other interests from the IP. The authors have no other conflicts of interest to declare.

Ethical Statement: The authors are accountable for all aspects of the work in ensuring that questions related to the accuracy or integrity of any part of the work are appropriately investigated and resolved. The study was conducted in accordance with the Declaration of Helsinki 
(as revised in 2013). The study is compliant with the Health Insurance Portability and Accountability Act, approved by the University of North Carolina at Chapel Hill (UNC) Institutional Review Board (No. UNC IRB 13-3345), and the data was obtained as part of a registered Clinical Trial at ClinicalTrials.gov (NCT02075320). Written and oral informed consent was obtained from each subject.

Open Access Statement: This is an Open Access article distributed in accordance with the Creative Commons Attribution-NonCommercial-NoDerivs 4.0 International License (CC BY-NC-ND 4.0), which permits the noncommercial replication and distribution of the article with the strict proviso that no changes or edits are made and the original work is properly cited (including links to both the formal publication through the relevant DOI and the license). See: https://creativecommons.org/licenses/by-nc-nd/4.0/.

\section{References}

1. Bach PB. Reduced lung-cancer mortality with CT screening. N Engl J Med 2011;365:2036; author reply 2037-8.

2. National Lung Screening Trial Research Team; Aberle DR, Adams AM, et al. Reduced lung-cancer mortality with low-dose computed tomographic screening. N Engl J Med 2011;365:395-409.

3. Gould MK, Tang T, Liu IL, et al. Recent Trends in the Identification of Incidental Pulmonary Nodules. Am J Respir Crit Care Med 2015;192:1208-14.

4. McWilliams A, Tammemagi MC, Mayo JR, et al. Probability of cancer in pulmonary nodules detected on first screening CT. N Engl J Med 2013;369:910-9.

5. MacMahon H, Naidich DP, Goo JM, et al. Guidelines for Management of Incidental Pulmonary Nodules Detected on CT Images: From the Fleischner Society 2017. Radiology 2017;284:228-43.

6. Mun M, Nakao M, Matsuura Y, et al. Video-assisted thoracoscopic surgery lobectomy for non-small cell lung cancer. Gen Thorac Cardiovasc Surg 2018;66:626-31.

7. Gould MK, Donington J, Lynch WR, et al. Evaluation of individuals with pulmonary nodules: when is it lung cancer? Diagnosis and management of lung cancer, $3 \mathrm{rd}$ ed: American College of Chest Physicians evidence-based clinical practice guidelines. Chest 2013;143:e93S-e120S.

8. Ng YL, Patsios D, Roberts H, et al. CT-guided percutaneous fine-needle aspiration biopsy of pulmonary nodules measuring $10 \mathrm{~mm}$ or less. Clin Radiol 2008;63:272-7.
9. Chen A, Chenna P, Loiselle A, et al. Radial probe endobronchial ultrasound for peripheral pulmonary lesions. A 5-year institutional experience. Ann Am Thorac Soc 2014;11:578-82.

10. Ost DE, Ernst A, Lei X, et al. Diagnostic Yield and Complications of Bronchoscopy for Peripheral Lung Lesions. Results of the AQuIRE Registry. Am J Respir Crit Care Med 2016;193:68-77.

11. Rueth NM, Parsons HM, Habermann EB, et al. The long-term impact of surgical complications after resection of stage I nonsmall cell lung cancer: a population-based survival analysis. Ann Surg 2011;254:368-74.

12. Chen A, Pastis N, Furukawa B, et al. The effect of respiratory motion on pulmonary nodule location during electromagnetic navigation bronchoscopy. Chest 2015;147:1275-81.

13. Pritchett MA, Bhadra K, Calcutt M, et al. Virtual or reality: divergence between preprocedural computed tomography scans and lung anatomy during guided bronchoscopy. J Thorac Dis 2020;12:1595-611.

14. Eberhardt R, Anantham D, Herth F, et al. Electromagnetic navigation diagnostic bronchoscopy in peripheral lung lesions. Chest 2007;131:1800-5.

15. Rittirak W, Sompradeekul S. Diagnostic yield of fluoroscopy-guided transbronchial lung biopsy in nonendobronchial lung lesion. J Med Assoc Thai 2007;90 Suppl 2:68-73.

16. Torrington KG, Kern JD. The utility of fiberoptic bronchoscopy in the evaluation of the solitary pulmonary nodule. Chest 1993;104:1021-4.

17. Nair A, Godoy MC, Holden EL, et al. Multidetector $\mathrm{CT}$ and postprocessing in planning and assisting in minimally invasive bronchoscopic airway interventions. Radiographics 2012;32:E201-32.

18. Schafer S, Nithiananthan S, Mirota DJ, et al. Mobile C-arm cone-beam CT for guidance of spine surgery: image quality, radiation dose, and integration with interventional guidance. Med Phys 2011;38:4563-74.

19. Bachar G, Barker E, Chan H, et al. Visualization of anterior skull base defects with intraoperative cone-beam CT. Head Neck 2010;32:504-12.

20. Schwartz JG, Neubauer AM, Fagan TE, et al. Potential role of three-dimensional rotational angiography and C-arm CT for valvular repair and implantation. Int J Cardiovasc Imaging 2011;27:1205-22.

21. Siewerdsen JH, Jaffray DA. Optimization of $x$-ray imaging geometry (with specific application to flat-panel conebeam computed tomography). Med Phys 2000;27:1903-14. 
22. Lechuga L, Weidlich GA. Cone Beam CT vs. Fan Beam CT: A Comparison of Image Quality and Dose Delivered Between Two Differing CT Imaging Modalities. Cureus 2016;8:e778.

23. Pritchett MA, Schampaert S, de Groot JAH, et al. ConeBeam CT With Augmented Fluoroscopy Combined With Electromagnetic Navigation Bronchoscopy for Biopsy of Pulmonary Nodules. J Bronchology Interv Pulmonol 2018;25:274-82.

24. Yang SM, Yu KL, Lin KH, et al. Real-time augmented fluoroscopy-guided lung marking for thoracoscopic resection of small pulmonary nodules. Surg Endosc 2020;34:477-84.

25. Dobbins JT 3rd, Godfrey DJ. Digital x-ray tomosynthesis: current state of the art and clinical potential. Phys Med Biol 2003;48:R65-106.

26. Dobbins JT 3rd, McAdams HP. Chest tomosynthesis: technical principles and clinical update. Eur J Radiol 2009; 72:244-51.

27. Johnsson AA, Vikgren J, Bath M. Chest tomosynthesis: technical and clinical perspectives. Semin Respir Crit Care Med 2014;35:17-26.

28. Gunnell ET, Franceschi DK, Inscoe CR, et al. Initial clinical evaluation of stationary digital chest tomosynthesis in adult patients with cystic fibrosis. Eur Radiol 2019;29:1665-73.

29. Wang J, Phi XA, Greuter MJW, et al. The costeffectiveness of digital breast tomosynthesis in a population breast cancer screening program. Eur Radiol 2020;30:5437-45.

30. Lowry KP, Trentham-Dietz A, Schechter CB, et al. LongTerm Outcomes and Cost-Effectiveness of Breast Cancer Screening With Digital Breast Tomosynthesis in the United States. J Natl Cancer Inst 2020;112:582-9.

31. Båth M, Svalkvist A, von Wrangel A, et al. Effective dose to patients from chest examinations with tomosynthesis. Radiat Prot Dosimetry 2010;139:153-8.

32. Vikgren J, Zachrisson S, Svalkvist A, et al. Comparison of chest tomosynthesis and chest radiography for detection of pulmonary nodules: human observer study of clinical cases. Radiology 2008;249:1034-41.

33. Sabol JM. A Monte Carlo estimation of effective dose in chest tomosynthesis. Med Phys 2009;36:5480-7.

34. Tutar IB, Managuli R, Shamdasani V, et al. Tomosynthesisbased localization of radioactive seeds in prostate brachytherapy. Med Phys 2003;30:3135-42.

35. Nelson $\mathrm{G}, \mathrm{Wu} \mathrm{M}$, Hinkel $\mathrm{C}$, et al. Improved targeting accuracy of lung tumor biopsies with scanning-beam digital $\mathrm{x}$-ray tomosynthesis image guidance. Med Phys 2016;43:6282.

36. Bachar G, Barker E, Nithiananthan S, et al. Threedimensional tomosynthesis and cone-beam computed tomography: an experimental study for fast, low-dose intraoperative imaging technology for guidance of sinus and skull base surgery. Laryngoscope 2009;119:434-41.

37. Wiest PW, Locken JA, Heintz PH, et al. CT scanning: a major source of radiation exposure. Semin Ultrasound CT MR 2002;23:402-10.

38. Johnsson ÅA, Vikgren J, Båth M. A retrospective study of chest tomosynthesis as a tool for optimizing the use of computed tomography resources and reducing patient radiation exposure. Acad Radiol 2014;21:1427-33.

39. Aliasgharzadeh A, Mihandoost E, Masoumbeigi M, et al. Measurement of Entrance Skin Dose and Calculation of Effective Dose for Common Diagnostic X-Ray Examinations in Kashan, Iran. Glob J Health Sci 2015;7:202-7.

40. Hwang HS, Chung MJ, Lee KS. Digital tomosynthesis of the chest: comparison of patient exposure dose and image quality between standard default setting and low dose setting. Korean J Radiol 2013;14:525-31.

41. Zhou W, Qian X, Lu J, et al. Multi-beam X-ray source breast tomosynthesis reconstruction with different algorithms. Proc SPIE Int Soc Opt Eng 2010;7622:76220H.

42. Qian X, Rajaram R, Calderon-Colon X, et al. Design and characterization of a spatially distributed multibeam field emission $\mathrm{x}$-ray source for stationary digital breast tomosynthesis. Med Phys 2009;36:4389-99.

43. Inscoe CR, Platin E, Mauriello SM, et al. Characterization and preliminary imaging evaluation of a clinical prototype stationary intraoral tomosynthesis system. Med Phys 2018;45:5172-85.

44. Wang Memoli JS, Nietert PJ, Silvestri GA. Metaanalysis of guided bronchoscopy for the evaluation of the pulmonary nodule. Chest 2012;142:385-93.

45. Steinfort DP, Khor YH, Manser RL, et al. Radial probe endobronchial ultrasound for the diagnosis of peripheral lung cancer: systematic review and meta-analysis. Eur Respir J 2011;37:902-10.

46. Zhang W, Chen S, Dong X, et al. Meta-analysis of the diagnostic yield and safety of electromagnetic navigation bronchoscopy for lung nodules. J Thorac Dis 2015;7:799-809.

47. Spronk D, Luo Y, Inscoe CR, et al. Evaluation of carbon nanotube $\mathrm{x}$-ray source array for stationary head computed 
tomography. Med Phys 2021;48:1089-99.

48. James TD, McAdams HP, Song JW, et al. Digital tomosynthesis of the chest for lung nodule detection: interim sensitivity results from an ongoing NIH-sponsored trial. Med Phys 2008;35:2554-7.

49. Uppot RN, Sahani DV, Hahn PF, et al. Impact of obesity on medical imaging and image-guided intervention. AJR Am J Roentgenol 2007;188:433-40.

Cite this article as: Burks AC, Akulian J, MacRosty CR, Ghosh S, Belanger A, Sakthivel M, Benefield TS, Inscoe CR, Zhou O, Lu J, Lee YZ. Feasibility of a prototype carbon nanotube enabled stationary digital chest tomosynthesis system for identification of pulmonary nodules by pulmonologists. J Thorac Dis 2022;14(2):257-268. doi: 10.21037/jtd-21-1381 